\title{
Lanthanum Manganite-based Air Electrode Catalysts and Their Application to Lithium-air Batteries: Effects of Carbon Support Oxidation
}

\section{Morihiro SAITO, ${ }^{a}, *$ Yusuke TACHIKAWA, ${ }^{a}$ Taichi FUJINAMI, ${ }^{a}$ Kento MIKAMI, ${ }^{a}$ Yoshiya HAYASHI, ${ }^{a}$ Hidenobu SHIROISHI, ${ }^{b}$ Daniel STREICH, ${ }^{\mathrm{c}}$ Erik J. BERG, ${ }^{\mathrm{c}}$ and Petr NOVÁKc}

\author{
a Department of Applied Chemistry, Tokyo University of Agriculture \& Technology, \\ 2-24-16 Naka-cho, Koganei, Tokyo 184-8588, Japan \\ b Department of Chemical Science and Engineering, National Institute of Technology, Tokyo College, \\ 1220-2 Kunugida, Hachioji, Tokyo 193-0997, Japan \\ c Electrochemistry Laboratory, Paul Scherrer Institut (PSI), CH-5232 Villigen PSI, Switzerland \\ * Corresponding author: mosaito@cc.tuat.ac.jp
}

\begin{abstract}
Acid-treated Ketjen Black (a-KB) carbon supports were prepared to investigate how oxidation of the carbon surface influences $\mathrm{La}_{0.6} \mathrm{Sr}_{0.4} \mathrm{MnO}_{3}$ (LSM) nanoparticle distribution, and conjugation to the carbon support. 30 wt.\% LSMloaded a-KB (LSM/a-KB) materials were prepared as air-electrode catalysts for rechargeable lithium-air batteries (LABS). a-KB exhibited a significant degree of O-containing (C-O, COO) surface functional groups, which resulted in the formation of smaller LSM nanoparticles and enhanced homogeneity over the carbon support when compared with the pristine KB support. Consequently, C-O-Mn bonds were formed, which increased the Mn oxidation state, and concomitantly enhanced conjugation resulting in improved catalytic activity. Additionally, the overpotential was reduced during charging ( $\mathrm{Li}_{2} \mathrm{O}_{2}$ decomposition). Furthermore, $\mathrm{LSM} / \mathrm{a}-\mathrm{KB}$ enhanced the cyclability of the LAB test cell. Scanning electron microscopy observations revealed that LSM/a-KB efficiently decomposed the $\mathrm{Li}_{2} \mathrm{O}_{2}$ deposition layer, even after the 15th charge cycle when compared with LSM/KB. The LSM/a-KB air-electrode exhibited a more homogeneous and smaller-sized (and/or amorphous) $\mathrm{Li}_{2} \mathrm{O}_{2}$ deposition after discharging. Therefore, the oxidation of the carbon surface, resulting in enhanced LSM nanoparticle distribution on, and conjugation to, the a-KB surface, influences the homogeneity of the $\mathrm{Li}_{2} \mathrm{O}_{2}$ deposition onto the support during the discharge process leading to its facile decomposition during the following charge process.
\end{abstract}

(c) The Electrochemical Society of Japan, All rights reserved.

Keywords : Air Electrode Catalyst, Lanthanum Manganite, Lithium-air Batteries, Carbon Support Oxidation

\section{Introduction}

In recent years, rechargeable lithium $(\mathrm{Li})$-air $\left(\mathrm{O}_{2}\right)$ batteries (LABs) have received increasing attention as next-generation, largescale energy storage systems because of their higher energy density of over $500 \mathrm{Wh} \mathrm{kg}^{-1}$-exceeding that of Li-ion batteries..$^{1-4}$ However, significant challenges of LAB systems still need to be addressed before practical use, e.g., suppression of $\mathrm{Li}$ dendrite growth at the $\mathrm{Li}$ metal negative electrode (NE), enhancing electrolyte electrochemical durability, especially against the $\mathrm{O}_{2}{ }^{-}$ radical generated at the air-electrode (positive electrode, PE), and exploration of highly active air-electrode catalysts for both the oxygen reduction reaction (ORR) and the oxygen evolution reaction (OER). ${ }^{3,5,6}$ Therefore, there has been a wealth of interdependent research focusing on air-electrode catalysts, e.g. noble metal nanoparticles $(\mathrm{Pt}, \mathrm{Au})^{7-13}$ and oxides $\left(\mathrm{Co}_{3} \mathrm{O}_{4}, \mathrm{RuO}_{2}, \mathrm{IrO}_{2}\right)^{14-20}$ loaded on carbon supports (Ketjen Black (KB), carbon nanotubes, graphene, etc.). However, the abundance of catalytic elements required is low resulting in their high costs. More realistic candidates that have been intensively researched and applied as air-electrodes for LABs include perovskite nanoparticle-based ${ }^{21-24}$ and $\mathrm{Mn}$ oxide-based ${ }^{25-29}$ catalysts. However, these solid catalysts are covered by $\mathrm{a} \mathrm{Li}_{2} \mathrm{O}_{2}$ deposition layer during the discharge process and are not sufficiently efficient to decompose this deposition layer during the charge process. ${ }^{30-34}$ Recent studies have focused on investigating mediators to chemically decompose the $\mathrm{Li}_{2} \mathrm{O}_{2}$ deposition layer such as $\mathrm{LiI},{ }^{30,31} \mathrm{LiBr},{ }^{32,33}$ 2,2,6,6-tetramethylpiperidinyloxyl (TEMPO) ${ }^{34}$ etc. However, it became apparent that the mediators self-discharged because of the direct reaction with the $\mathrm{Li}$ metal NE, i.e., the shuttle effect. ${ }^{35}$ Additionally, complications arise with the chemical and electrochemical cycling of the mediators as a result of side reactions. Therefore, continuing investigations into solid catalysts remain important to improve LAB systems. Recently, various solid catalyst morphologies have been proposed to include oxide nanotubes, ${ }^{36}$ mesoporous nanowires, ${ }^{37}$ and nanosheets, ${ }^{38}$ and these composites with nano-carbon materials (carbon nanotubes, graphene, etc.). ${ }^{39}$ The rationale is to increase the surface area, and concomitantly the number of catalytic sites to enhance the electron path. Consequently, such catalysts have successfully reduced the overpotential during the charge process and extended the cyclability. However, the influence of increased catalyst surface area and maintaining the electron path during $\mathrm{Li}_{2} \mathrm{O}_{2}$ decomposition remains unclear as the solid catalysts are coated by a $\mathrm{Li}_{2} \mathrm{O}_{2}$ deposition layer during the discharge process. ${ }^{30-34}$ To elucidate the critical point on how to improve the catalytic activity of solid catalysts, in this study we synthesized two types of $\mathrm{La}_{0.6} \mathrm{Sr}_{0.4} \mathrm{MnO}_{3}$ (LSM)-loaded $\mathrm{KB}$ catalysts. Each catalyst differed in their LSM nanoparticle distribution on the carbon support and in the conjugation of the support-LSM nanoparticle interaction. Namely, the aforementioned properties were controlled by surface oxidation of the KB powder, which led to improved affinity of the LSM precursor to the KB nanoparticle surface, enabling smaller LSM nanoparticles on the 
carbon support and improved conjugation between the LSM and KB nanoparticles by formation of C-O-Mn bonds. The nature of the two catalysts allowed the influence of increased catalyst surface area to be investigated while maintaining the electron path during $\mathrm{Li}_{2} \mathrm{O}_{2}$ decomposition in the LAB system.

\section{Experimental}

\subsection{Synthesis of LSM/acid-treated KB (a-KB) catalyst (LSM/a- $\mathrm{KB})$}

First, a-KB was obtained by adding $200 \mathrm{mg}$ of $\mathrm{KB}$ powder (EC600JD, Lion Corp. Ltd.) to an $80 \mathrm{~mL}(60 \mathrm{wt} \%) \mathrm{LiNO}_{3}$ aqueous solution (Wako Pure Chemicals) under stirring at $100^{\circ} \mathrm{C}$ for $3 \mathrm{~h}$ to subject the $\mathrm{KB}$ surface to oxidation. a-KB was filtered, washed with copious amounts of deionized $\mathrm{H}_{2} \mathrm{O}$ and dried at $80^{\circ} \mathrm{C}$ overnight. The LSM/a-KB catalyst was synthesized by modifying a previous "nanometer-sized crystal formation in alcoholic solutions" (NACFAS) method. ${ }^{40} \mathrm{La}\left(\mathrm{NO}_{3}\right)_{3} \cdot 6 \mathrm{H}_{2} \mathrm{O}$ (Wako Pure Chemicals, 99.9\%), $\mathrm{Sr}\left(\mathrm{NO}_{3}\right)_{2}$ (Wako Pure Chemicals, 98.0\%) and $\mathrm{Mn}\left(\mathrm{NO}_{3}\right)_{2} \cdot 6 \mathrm{H}_{2} \mathrm{O}$ (Sigma-Aldrich, 98.0\%) were dissolved in deionized water to prepare a $2.0 \mathrm{M}$ aqueous solution of $\mathrm{La}^{3+}, \mathrm{Sr}^{2+}$ and $\mathrm{Mn}^{2+}$ mixed ions, where the molar ratio was $3: 2: 5$, respectively. $15 \mathrm{~mL}$ of ethanol (Wako Pure Chemicals, $99.5 \%$ ) was added to $2.0 \mathrm{~mL}$ of the mixed ion solution before stirring in an ultrasonic bath (frequency: $40 \mathrm{kHz}$ ) at $10^{\circ} \mathrm{C}$ for $1 \mathrm{~h}$. After an additional ultrasonic dispersion for $5 \mathrm{~min}$, the a-KB powder was added at the desired amount to yield a $20 \mathrm{wt}$ \% LSM/a-KB catalyst before further subjecting the system to ultrasonication for $1 \mathrm{~h}$. The LSM precursor-loaded a-KB powder was filtered and washed with copious amounts of deionized $\mathrm{H}_{2} \mathrm{O}$, and then further dispersed in ethanol by ball-milling for $30 \mathrm{~min}$. Thereafter, the sample was dried at $70^{\circ} \mathrm{C}$ before calcining under an Ar atmosphere at $600^{\circ} \mathrm{C}$ for $5 \mathrm{~h}$ to obtain the LSM/a-KB catalyst. As a comparison sample, a $20 \mathrm{wt} . \% \mathrm{LSM} / \mathrm{KB}$ catalyst was also synthesized using the pristine $\mathrm{KB}$ powder by the same manner.

\subsection{Characterization}

The obtained a-KB sample was characterized by transmission electron microscopy (TEM, JEM-1400, JEOL), Raman spectroscopy (RamanTouch-VIS-NIR, Nanophoton) with laser wavelength of $532 \mathrm{~nm}$ and spatial resolution of $350 \mathrm{~nm}$, Brunauer-Emmett-Teller (BET) method (BELLSORP-miniII, Micro-tracBEL) and X-ray photoelectron spectroscopy (XPS, PHI X-tool, ULVAC-PHI, INC.) with X-ray beam of Al-K $\alpha$ and the spot size of $10-300 \mathrm{~mm}$ to evaluate the morphology, degree of graphitization, specific surface area $\left(S_{\mathrm{BET}}\right)$ and functional groups on the carbon support. The data was compared with those of the pristine $\mathrm{KB}$ and discussed effects by the carbon support oxidation. To evaluate the crystal phase and morphology of the obtained LMS/a-KB and LSM/KB samples, powder X-ray diffraction (XRD, SmartLab, Rigaku) with X-ray beam of $\mathrm{Cu}-\mathrm{K} \alpha$, scanning electron microscopy (SEM, JSM-7800F, JEOL) and the same TEM for the a-KB were used, respectively. The catalyst composition with respect to LSM and KB was estimated by thermogravimetry-differential thermal analysis (TG-DTA, Thermo plus TG8120, Rigaku) from room temperature to $800^{\circ} \mathrm{C}$ at a scan rate of $10^{\circ} \mathrm{C} \mathrm{min}^{-1}$. The chemical and oxidation states of LSM together with the functional groups on the carbon supports for LSM/ $\mathrm{KB}$ and LSM/a-KB samples were also analyzed by the same XPS for the $\mathrm{a}-\mathrm{KB}$.

\subsection{LAB cell performance and air-electrode evaluation}

First, $100 \mathrm{mg}$ of the obtained $20 \mathrm{wt} . \%$ LSM/a-KB catalyst was mixed with $92.5 \mathrm{mg}$ of $12 \mathrm{wt} . \%$ polyvinylidene difluoride (PVDF) dissolved in N-methyl-2-pyrrolidone (NMP, Kureha) as a binder to form a slurry, which was thereafter coated on carbon paper (TGP-H060 , Toray) before drying at $110^{\circ} \mathrm{C}$ under vacuum overnight to prepare the air-electrode. As references, air-electrodes comprising
$20 \mathrm{wt} . \%$ of the LSM/KB catalyst were also prepared in the same manner. The air-electrodes were cut into circles $(\phi=16 \mathrm{~mm}$; i.e., $\mathrm{PE}$ apparent area was ca. $2 \mathrm{~cm}^{2}$ ). The Swagelok-type LAB test cell comprised the obtained air-electrode, Li metal foil (thickness: $0.5 \mathrm{~mm}$, Honjo Metal Co., Ltd.) as the NE, a separator (Celgard1 $2400)$, and $0.20 \mathrm{M} \mathrm{LiN}\left(\mathrm{SO}_{2} \mathrm{CF}_{3}\right)_{2} /$ diglyme (LiTFSI/G2) $\left(\mathrm{H}_{2} \mathrm{O}\right.$ content: $<30 \mathrm{ppm}$ ) as the electrolyte and was prepared in an argon-filled glove box (Miwa, MDB-1BK-NT1) with a dew point below $-70^{\circ} \mathrm{C} .{ }^{38}$ The electrolyte was prepared by mixing LiTFSI (Kishida, 99.9\%) and G2 (Tokyo Chemical Industry Co., Ltd.). For the discharge/charge cycle test, an applied current of $0.20 \mathrm{~mA} \mathrm{~cm}^{-2}$ and a maximum discharge/charge capacity of $0.50 \mathrm{mAh} \mathrm{cm}^{-2}$ were applied to the LAB cell across the cut-off voltage range of 2.0 to 4.5 V. To prevent the G2-based electrolyte solution from drying out, the LAB test cell was operated in a passive mode and supplied with pure $\mathrm{O}_{2}$ gas. The LAB cell was cycled up to 30 times. To observe the $\mathrm{Li}_{2} \mathrm{O}_{2}$ deposition and decomposition behaviors, a maximum discharge/charge capacity of $1.0 \mathrm{mAh} \mathrm{cm}^{-2}$ was also applied to the LAB cell with the same applied current and cut-off voltage range. Morphology observations and elemental analysis on the surface of the air-electrode before and after the discharge/charge test were conducted by scanning electron microscopy-energy dispersive X-ray spectroscopy (SEM-EDS, JSM-7800F, JEOL). The $\mathrm{Li}_{2} \mathrm{O}_{2}$ produced on the air-electrodes was confirmed by XRD (D8 ADVANCE, Bruker). Both the SEM observations and the XRD analysis of the air-electrodes after the LAB cell test were conducted using a transfer vessel to prevent exposure to air. In addition, to determine the maximum capacity of the LAB test cell and the effect of the LSM/a-KB catalyst, no capacity limitation test was also conducted only for the first cycle. All electrochemical measurements were performed at $30^{\circ} \mathrm{C}$.

\section{Results and Discussion}

\subsection{LSM/a-KB catalyst and air-electrode characterization}

Figures 1(a) and (b) show the TEM micrographs of the KB and $\mathrm{a}-\mathrm{KB}$ carbon supports, respectively. The a-KB nanoparticles were partly corroded after being subjected to the acid-treatment, which resulted in deformation of the nanoparticles. Raman spectra (Fig. 1(c)) clearly exhibited a D-band at $1350 \mathrm{~cm}^{-1}$ and a G-band at $1590 \mathrm{~cm}^{-1}$, corresponding to defects and increased graphitized sites, respectively. The $\mathrm{G} / \mathrm{D}$ ratio for a-KB (0.82) increased compared with that of the pristine $\mathrm{KB}(0.76)$, indicating that some of the KB defect sites were removed by surface oxidation as a result of the acid-treatment with no loss of integrity of the graphitized sites. Additionally, $S_{\mathrm{BET}}$ increased from $1381 \mathrm{~m}^{2} \mathrm{~g}^{-1}$ for $\mathrm{KB}$ to $1864 \mathrm{~m}^{2} \mathrm{~g}^{-1}$ for a-KB. Furthermore, the specific pore volume increased from $1.88 \mathrm{~cm}^{3} \mathrm{~g}^{-1}$ for $\mathrm{KB}$ to $2.48 \mathrm{~cm}^{3} \mathrm{~g}^{-1}$ for $\mathrm{a}-\mathrm{KB}$. Figures $1(\mathrm{~d})$ and (e) show the XPS $\mathrm{C} 1 \mathrm{~s}$ spectra for the KB and a-KB carbon supports. $\mathrm{KB}$ exhibited an intense peak located at $284.3 \mathrm{eV}$ assigned to the $\mathrm{C}-\mathrm{C}$ bond, and low intensity peaks located at 286.2 and $289.5 \mathrm{eV}$ corresponding to $\mathrm{C}-\mathrm{O}$ and $\mathrm{COO}$ bonds, respectively. ${ }^{41}$ The $\mathrm{O}$-containing peaks were enhanced for a-KB and an additional peak appeared at $287.8 \mathrm{eV}$ corresponding to the $\mathrm{C}=\mathrm{O}$ bond. Therefore, KB acid-treatment, i.e., surface oxidation of $\mathrm{KB}$ nanoparticles, was clearly confirmed.

Figure 2(a) presents XRD patterns of the $\mathrm{KB}$, a-KB, LSM/KB and LSM/a-KB samples. For the air-electrode catalysts, the LSM nanoparticles were successfully synthesized within the catalysts and the XRD peaks corresponding to LSM in LSM/a-KB are broader when compared with LSM in the presence of the pristine $\mathrm{KB}$ support. The crystallite size estimated from the XRD peak at around $32^{\circ}$ by the Scherrer equation is $24 \mathrm{~nm}$, which is smaller than that for LSM in LSM/KB $(31 \mathrm{~nm})$. Additionally, from the SEM and TEM micrographs (Figs. 2(b-e)), the average particle size is observed to be $>100 \mathrm{~nm}$ for $\mathrm{KB}$ and $50-80 \mathrm{~nm}$ for a-KB. It is evident that the 

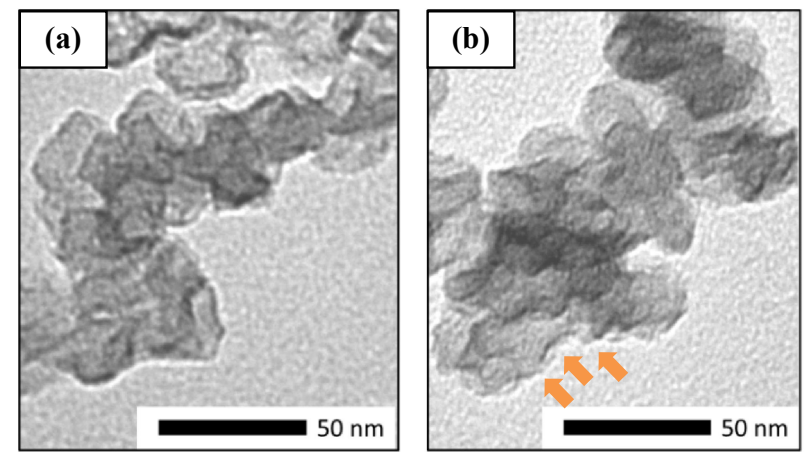

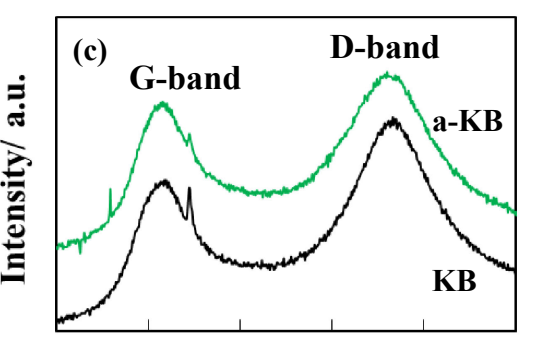

$17001600150014001300 \quad 1200$

Raman shift/ $\mathbf{c m}^{-1}$
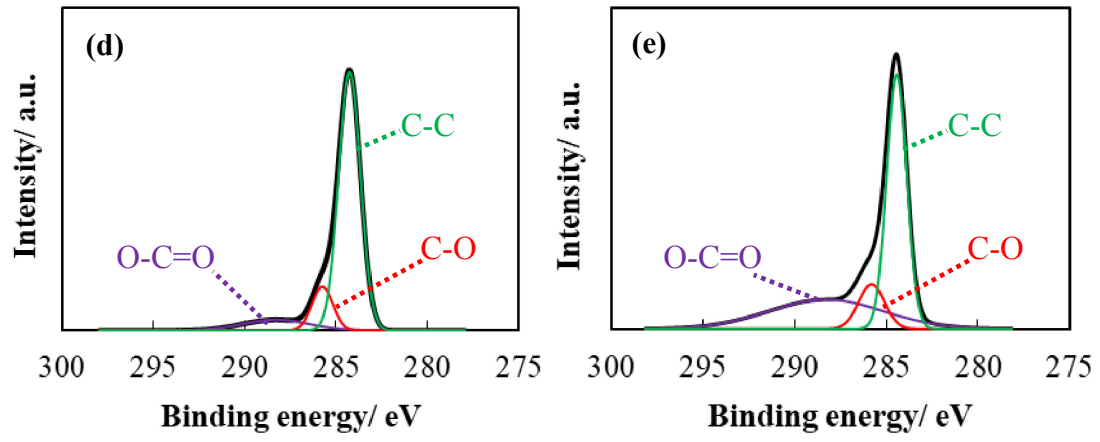

Figure 1. Transmission electron microscope (TEM) images of: (a) Ketjen Black (KB) and (b) acid-treated KB (a-KB). (c) Raman spectra of the carbon supports. X-ray photoelectron spectroscopy (XPS) C 1s spectra of: (d) KB and (e) a-KB. The arrows in (b) show the removal parts of $\mathrm{KB}$ defect sites.
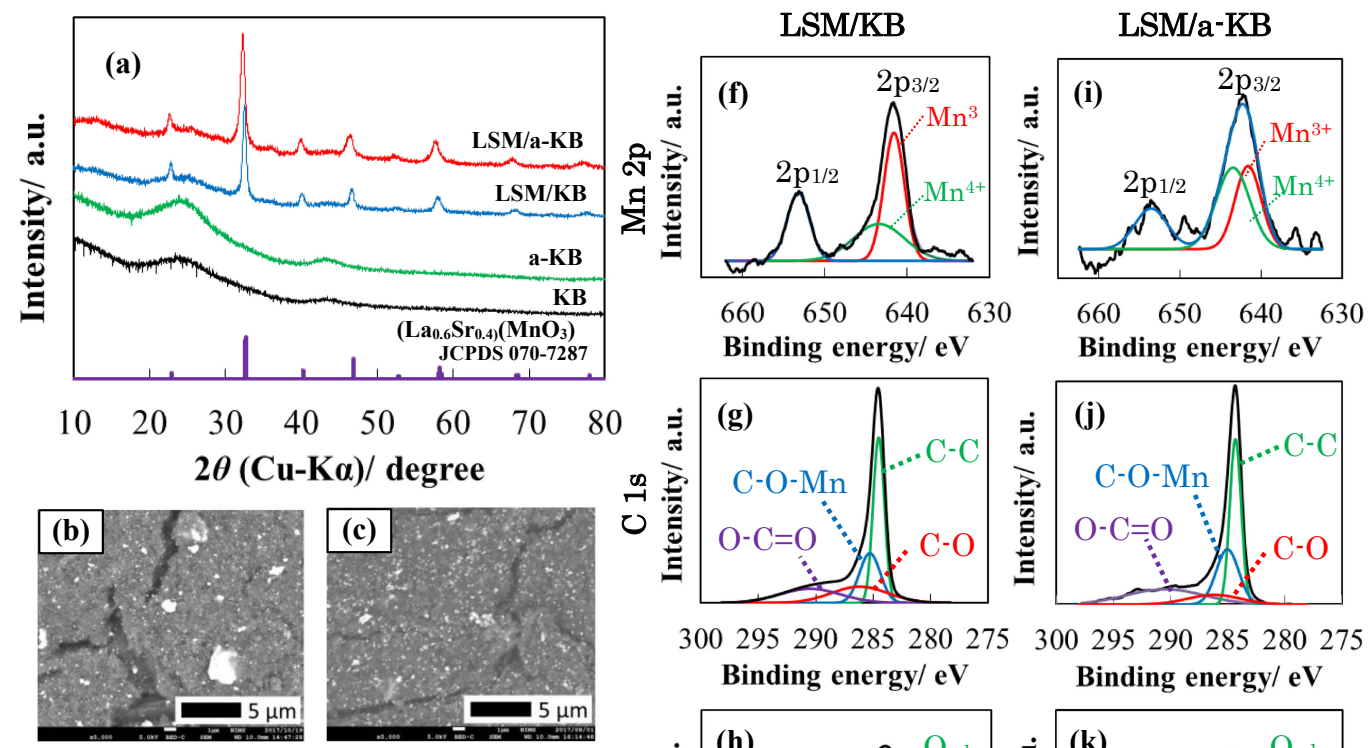

300295290285280275300295290285280275

Binding energy/ eV

Binding energy/ eV
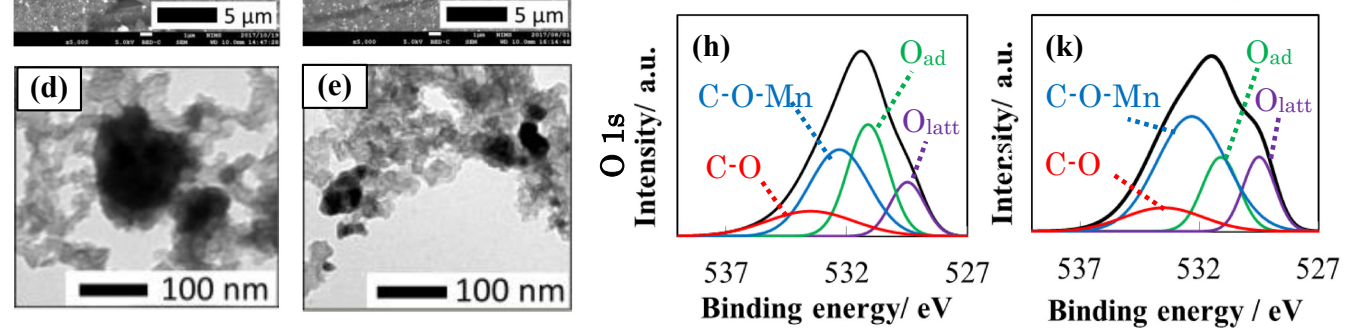

Figure 2. (a) X-ray diffraction (XRD) patterns of a-KB and the $\mathrm{La}_{0.6} \mathrm{Sr}_{0.4} \mathrm{MnO}_{3}$ (LSM)/a-KB catalyst. (b-c) Scanning electron microscopy (SEM) and (d-e) TEM micrographs of: (b, d) LSM/KB and (c, e) LSM/a-KB catalysts. (f, i) Mn 2p, (g, j) C 1s and (h, k) O 1s XPS spectra for (f-h) LSM/KB and (i-k) LSM/a-KB catalysts.

LSM distribution on the carbon support in the LSM/a-KB catalyst was more homogeneous and having smaller nanoparticles than in the corresponding LSM/KB catalyst. Namely, surface oxidation of
KB effectively improved the affinity of the LSM precursor to the carbon support and promoted to reduce both crystallite and particle sizes of LSM after calcining under an Ar atmosphere. LSM loading 

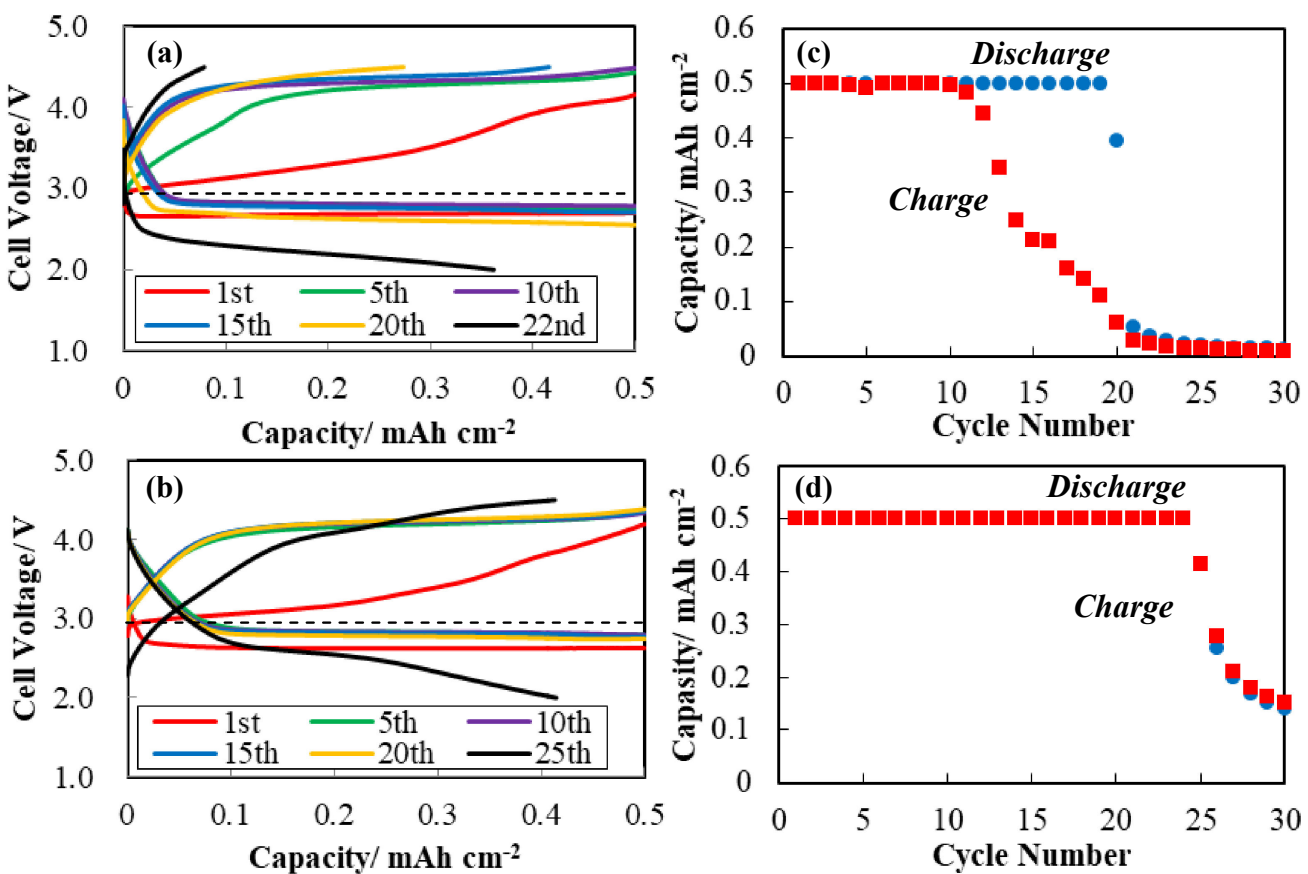

Figure 3. (a-b) Discharge/charge curves (maximum current: $0.5 \mathrm{mAh} \mathrm{cm}^{-2}$ ) and (c-d) cyclability of the lithium-air battery (LAB) test cells using $(\mathrm{a}, \mathrm{c}) \mathrm{LSM} / \mathrm{KB}$ and $(\mathrm{b}, \mathrm{d}) \mathrm{LSM} / \mathrm{a}-\mathrm{KB}$ air-electrode catalysts at $30^{\circ} \mathrm{C}$.

levels were derived from TG-DTA analysis. The LSM content in the $\mathrm{LSM} / \mathrm{KB}$ and LSM/a-KB product catalysts is 19.2 and $22.7 \mathrm{wt} . \%$, respectively (data not shown), which is close to that of the estimated value from the starting materials $(20 \mathrm{wt} . \%)$. The slight increase in LSM content in the LSM/a-KB catalyst is considered to be attributed to the O-containing functional groups on the carbon surface, which results in a degree of decomposition of the $\mathrm{KB}$ surface when subjecting the LSM nanoparticles to calcination at $600^{\circ} \mathrm{C}$ for $5 \mathrm{~h}$ under an $\mathrm{Ar}$ atmosphere. This is supported by the TGDTA curves (data not shown). Figures $2(\mathrm{f}-\mathrm{k})$ shows the XPS C 1s, Mn $2 p$ and $O$ 1s spectra for the LSM/KB and LSM/a-KB catalysts. After loading the LSM nanoparticles, the $\mathrm{C} 1 \mathrm{~s}$ spectra for both carbon supports exhibited $\mathrm{C}-\mathrm{O}$ and $\mathrm{COO}$ bonds at 286.2 and $289.5 \mathrm{eV}$, respectively. The intensity of both spectra increased to similar levels compared with the corresponding spectra prior to LSM loading. Additionally, a new peak owing to C-O-Mn bonds appeared at $285.2 \mathrm{eV}$, which was enhanced for the LSM/a-KB catalyst. This was supported by the $\mathrm{O} 1 \mathrm{~s}$ spectra for the catalysts, were four peaks were confirmed after deconvoluting at 529.5, 531.1, 532.3 and $533.5 \mathrm{eV}$, corresponding to LSM lattice $\mathrm{O}$, adsorbed $\mathrm{O}$, $\mathrm{C}-\mathrm{O}-\mathrm{Mn}$ and $\mathrm{C}-\mathrm{O}$, respectively. ${ }^{42}$ The $\mathrm{C}-\mathrm{O}-\mathrm{Mn}$ peak was clearly enhanced for the LSM/a-KB catalyst together with the LSM nanoparticle lattice $\mathrm{O}$. Therefore, there is enhanced conjugation between the LSM nanoparticles and the carbon support in the presence of O-containing functional groups. As a result, the Mn $2 p$ spectra were shifted from Mn 2p $\mathrm{p}_{3 / 2}: 641.7 \mathrm{eV}$ and $\operatorname{Mn} 2 \mathrm{p}_{1 / 2}$ : $653.3 \mathrm{eV}$ for the LSM/KB catalyst to $\mathrm{Mn} 2 \mathrm{p}_{3 / 2}: 642.1 \mathrm{eV}$ and Mn $2 \mathrm{p}_{1 / 2}: 653.6 \mathrm{eV}$ for the LSM/a-KB catalyst. ${ }^{43}$ Hence, the Mn oxidation state increased as a function of C-O-Mn bond formation, meaning that the ratio of $\mathrm{Mn}^{4+} / \mathrm{Mn}^{3+}$ increased and influenced ORR and OER catalytic activity. This is in good agreement with the trends observed for the $\mathrm{C} 1 \mathrm{~s}$ and $\mathrm{O} 1 \mathrm{~s}$ spectra. Therefore, the analysis demonstrates that the surface oxidation of the $\mathrm{KB}$ powder successfully enhanced distribution of the nanoparticles and improved conjugation between the LSM nanoparticles and the surface of the carbon support. How the catalysts effect the discharge/charge behavior, i.e., the $\mathrm{Li}_{2} \mathrm{O}_{2}$ generation/decomposition reaction, in the $\mathrm{LAB}$ test cell is discussed in section 3.2.

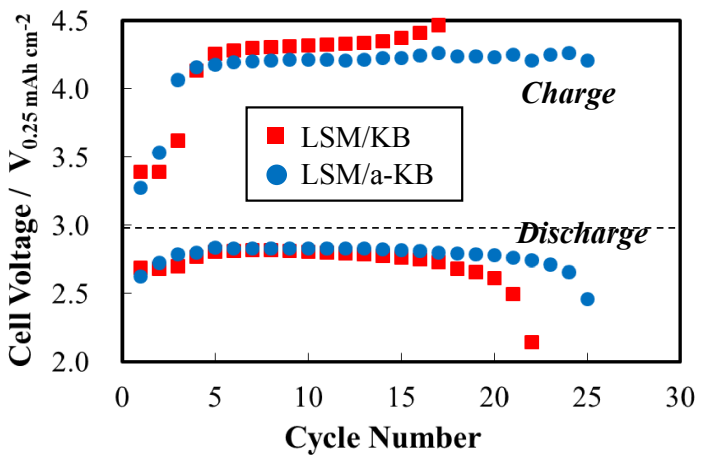

Figure 4. Overpotential values at $0.25 \mathrm{mAh} \mathrm{cm}^{-2}$ for the $\mathrm{LAB}$ test cells using different air-electrode catalysts at $30^{\circ} \mathrm{C}$.

\subsection{LAB cell performance evaluation}

Figure 3 shows the discharge/charge curves $(a-b)$ and the cyclability (c-d) of the LAB test cells using the LSM/KB and LSM/a-KB catalysts. During the initial discharge, both catalysts exhibited similar average cell voltages of $2.65-2.70 \mathrm{~V}$, which is lower than the LAB theoretical cell voltage $(2.96 \mathrm{~V})$. However, the overpotential during the charge process reduced in the presence of the LSM/a-KB catalyst (Fig. 4). After the second cycle, the overpotential during both the discharge and charge cycling process further reduced for the LSM/a-KB catalyst and maintained stability up to 24th cycle-such observations are in good agreement with the above-mentioned characterization results. Hence, the influence of the a-KB surface in changing the homogeneity of the LSM nanoparticle distribution and the conjugation to the a-KB carbon support was successfully demonstrated. Furthermore, the catalytic activity of LSM for both ORR and OER was improved as a result of the changes to the electronic structure owing to enhanced conjugation to the carbon support. ${ }^{43}$ These reduced the local current density at the surface of air-electrode, resulting in the decrease of the overpotential. 

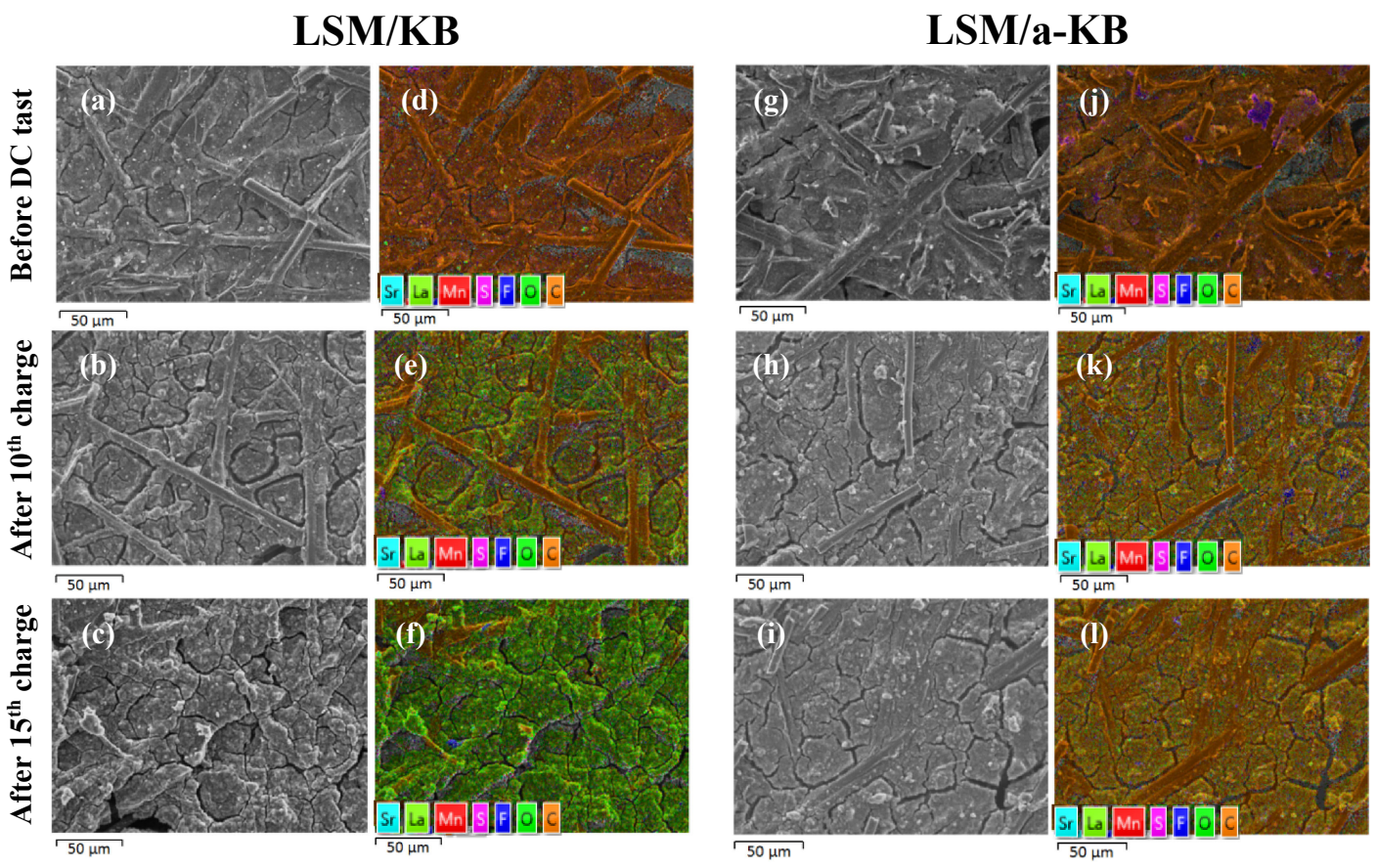

Figure 5. (a-c, g-i) SEM and (d-f, j-l) energy-dispersive X-ray spectroscopy (EDS) images before (a, d, g, j) the discharge/charge test and after the $(b, e, h, k)$ 10th and $(c, f, i, 1) 15$ th charge cycles for the LAB test cells using (a-f) LSM/KB and (g-l) LSM/a-KB air-electrode catalysts at $30^{\circ} \mathrm{C}$.

\section{3 $\mathrm{Li}_{2} \mathrm{O}_{2}$ deposition/decomposition behavior over the air- electrode surface}

To clarify how the $\mathrm{LSM} / \mathrm{a}-\mathrm{KB}$ catalyst influences $\mathrm{Li}_{2} \mathrm{O}_{2}$ decomposition during the charge process, SEM observations of the air-electrode were conducted prior to the discharge/charge test and after the 10th and 15th charge cycles. The results are shown in Fig. 5. For the LSM/KB catalyst, the green domain, corresponding to $\mathrm{Li}_{2} \mathrm{O}_{2}$ deposition, appeared to possess a high degree of roughness after the 10th charge cycle, with the roughness significantly increasing after the 15 th charge cycle. Conversely, the amount of remained $\mathrm{Li}_{2} \mathrm{O}_{2}$ deposition was relatively few and homogeneously removed for the LSM/a-KB catalyst even after 15th charging.

Figure 6 shows the SEM images of the air-electrodes after the first discharge and the following charge. To observe the homogeneity of the $\mathrm{Li}_{2} \mathrm{O}_{2}$ deposition more clearly, the limited capacity was doubled $\left(1.0 \mathrm{mAh} \mathrm{cm}^{-2}\right)$ compared with the data from Fig. 5. SEM observations reveal differences between the morphologies of the $\mathrm{Li}_{2} \mathrm{O}_{2}$ deposition on the catalysts. LSM/a-KB exhibits the highest degree of homogeneity in relation to $\mathrm{Li}_{2} \mathrm{O}_{2}$ deposition on the airelectrode, and after charging, the air-electrode morphology remains similar. Conversely, the air-electrode of the LSM/KB catalyst exhibited many cracks after charging, which were attributed to the damage caused by the rough and inhomogeneous $\mathrm{Li}_{2} \mathrm{O}_{2}$ deposition during the first discharge process. Additionally, the XRD peaks corresponding to $\mathrm{Li}_{2} \mathrm{O}_{2}$ broaden for the LSM/a-KB catalyst, indicating a smaller crystallite size (and/or more amorphous) and enhanced distributed over the air-electrode by the catalytic effect. Therefore, decomposition of the $\mathrm{Li}_{2} \mathrm{O}_{2}$ deposition layer was easier in the presence of the LSM/a-KB catalyst. As a result, no capacity limitation test exhibited enhanced maximum capacity-up to $6201 \mathrm{mAh} \mathrm{g}^{-1}$ (LSM/a-KB) from $5670 \mathrm{mAh} \mathrm{g}^{-1}$ (LSM/KB).

\section{Conclusions}

The catalytic activity of carbon-supported LSM catalysts was investigated to determine how the KB surface properties influences LSM nanoparticle distribution and conjugation to the carbon support. a-KB resulted in changes to the surface composition with an abundance of O-containing functional groups having excellent affinity to the LSM precursor. After calcination, the LSM nanoparticles reduced in size allowing the formation of C-O-Mn bonds with the carbon support. As a result, the overpotential for the LAB test cell, in the presence of the LSM/a-KB catalyst, was effectively reduced, especially during the charge process. Additionally, the cyclability improved compared with LSM/KB. SEM observations and XRD analysis of the air-electrodes demonstrated the effect of the $\mathrm{LSM} / \mathrm{a}-\mathrm{KB}$ catalysts on the deposition morphology of $\mathrm{Li}_{2} \mathrm{O}_{2}-$ enhanced homogeneity and smaller (or amorphous) $\mathrm{Li}_{2} \mathrm{O}_{2}$, suggesting facile decomposition of $\mathrm{Li}_{2} \mathrm{O}_{2}$ at the air-electrode during the charge process.

In general, solid catalysts are disadvantaged when applied to LAB cell systems because the catalyst is easily coated by the $\mathrm{Li}_{2} \mathrm{O}_{2}$ discharge product. During charging, it is difficult to completely decompose $\mathrm{Li}_{2} \mathrm{O}_{2}$. Therefore, there has been a recent focus to employ mediators having a function to chemically decompose $\mathrm{Li}_{2} \mathrm{O}_{2} \cdot{ }^{30-34}$ However, the smaller the nanoparticles in the solid catalyst and the better they are distributed, the more $\mathrm{Li}_{2} \mathrm{O}_{2}$ deposition on the carbon support is suppressed (and more uniform) enabling facile $\mathrm{Li}_{2} \mathrm{O}_{2}$ decomposition. Y.J. Park et al. reported on the synergistic effect of the solid catalyst and mediator for $\mathrm{Li}_{2} \mathrm{O}_{2}$ decomposition. ${ }^{44}$ The surface oxidation of $\mathrm{KB}$ was effective to enhance the LSM nanoparticle distribution and to reduce the nanoparticle size. The key factor to extend the solid catalyst reversibility is the generation of a homogeneous $\mathrm{Li}_{2} \mathrm{O}_{2}$ deposition layer. In conclusion, such solid catalysts remain important to achieve improved commercial LAB cell performance, and further exploration of combined solid catalysts and mediators will open up nextgeneration air-electrodes.

\section{Supporting Information}

The Supporting Information is available on the website at DOI: https://doi.org/10.5796/electrochemistry.18-00034. 


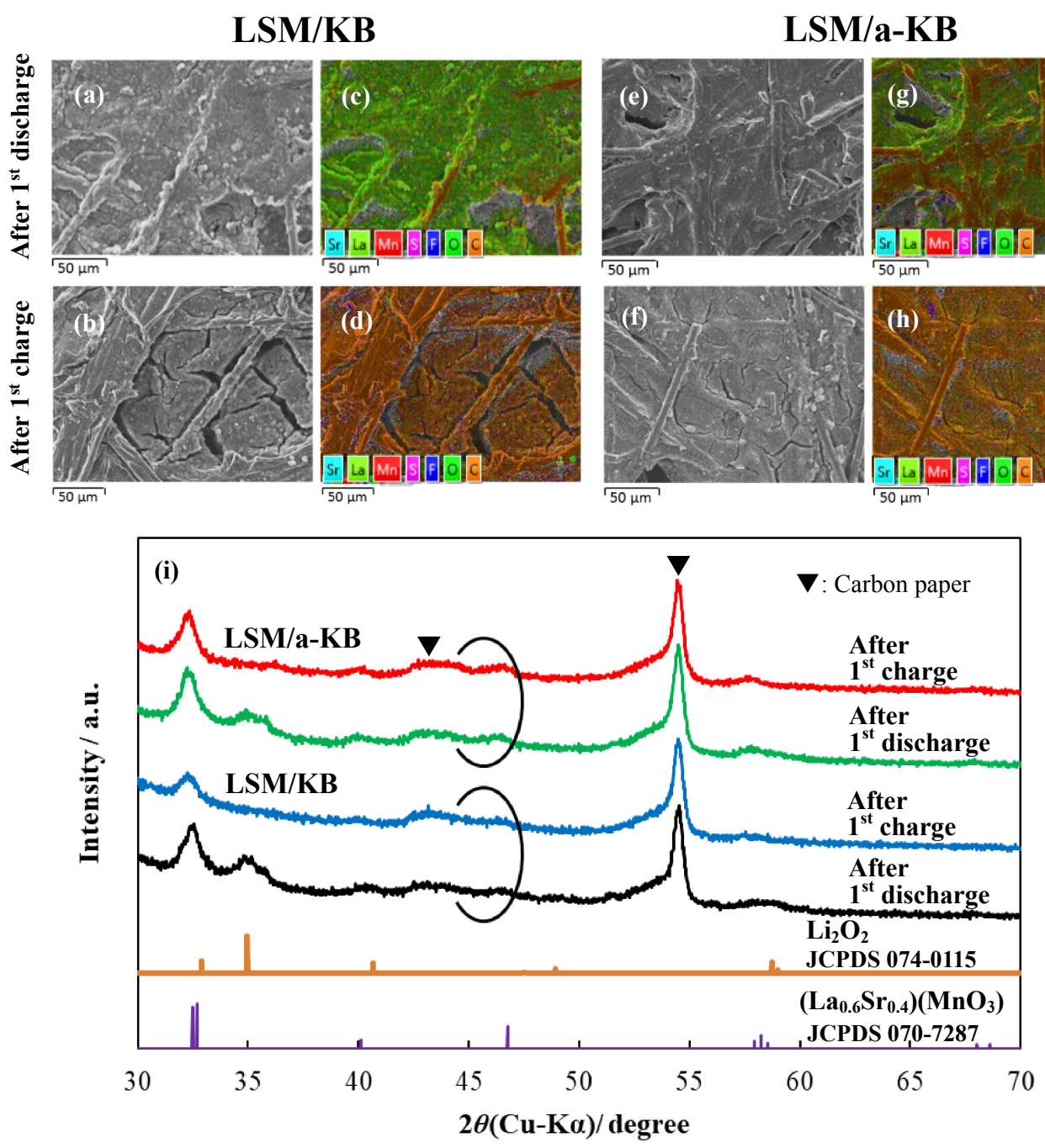

Figure 6. (a, b, e, f) SEM and (c, d, g, h) EDS images after (a, c, e, g) the first discharge and (b, d, f, h) the first charge for the LAB test cells using (a-d) LSM/KB and (e-h) LSM/a-KB air-electrode catalysts at $30^{\circ} \mathrm{C}$. (i) XRD patterns after the first discharge.

\section{Acknowledgments}

This work was supported by a scientific technology human resource development fee grant from JST ("Program to Disseminate Tenure Tracking System”), and a JSPS “KAKENHI” (25870899) grant from MEXT, Japan. We express special thanks to Dr. Y. Kubo from the National Institute for Materials Science (NIMS) for fruitful discussions.

\section{References}

1. K. M. Abraham and Z. Jiang, J. Electrochem. Soc., 143, 1 (1996).

2. T. Ogasawara, A. Débart, M. Holzapfel, P. Novák, and P. G. Bruce, J. Am. Chem. Soc., 128, 1390 (2006)

3. G. Girishkumar, B. McCloskey, A. C. Luntz, S. Swanson, and W. Wilcke, J. Phys. Chem. Lett., 1, 2193 (2010).

4. P. G. Bruce, S. A. Freunberger, L. J. Hardwick, and J. M. Tarascon, Nat. Mater, 11, 19 (2012)

5. D. Zhang, Z. Fu, Z. Wei, T. Huang, and A. Yu, J. Electrochem. Soc., 157, A362 (2010).

6. J. Suntivich, K. J. May, H. A. Gasteiger, J. B. Goodenough, and Y. Shao-Horn, Science, 334, 1383 (2011).

7. E. Yeager, Electrochim. Acta, 29, 1527 (1984).

8. Y.-C. Lu, H. A. Gasteiger, M. C. Parent, V. Chiloyan, and Y. Shao-Horn, Electrochem. Solid-State Lett., 13, A69 (2010).

9. Y.-C. Lu, Z. Xu, H. A. Gasteiger, S. Chen, K. Hamad-Schifferli, and Y. ShaoHorn, J. Am. Chem. Soc., 132, 12170 (2010).

10. W. Wang, R. F. Wang, S. Ji, H. Feng, H. Wang, and Z. Lei, J. Power Sources, 195
$3498(2010)$.

11. H. Wang, R. Wang, H. Li, Q. Wang, J. Kang, and Z. Lei, Int. J. Hydrogen Energy, 36, 839 (2011).

12. J. Wang, H. Wu, D. Gao, S. Miao, G. Wang, and X. Bao, Nano Energy, 13, 387 (2015).

13. M. Sevim, C. Francia, J. Amici, S. Vankova, T. Șener, and Ö. Metin, J. Alloys Compd., 683, 231 (2016).

14. A. Débart, J. Bao, G. Armstrong, and P. G. Bruce, J. Power Sources, 174, 1177 (2007).

15. A. Débart, A. J. Paterson, J. Bao, and P. G. Bruce, Angew. Chem., Int. Ed., 47, 4521 (2008).

16. L. Wang, X. Zhao, Y. Lu, M. Xu, D. Zhang, R. S. Ruoff, K. J. Stevenson, and J. B. Goodenough, J. Electrochem. Soc., 158, A1379 (2011).

17. J. Xu, P. Gao, and T. S. Zhao, Energy Environ. Sci., 5, 5333 (2012).

18. J. Suntivich, E. E. Perry, H. A. Gasteiger, and Y. Shao-Horn, Electrocatal., 4, 49 (2013).

19. L. Grande, E. Paillard, J. Hassoun, J. B. Park, Y. J. Lee, Y.-K. Sun, S. Passerini, and B. Scrosati, Adv. Mater., 27, 784 (2015).

20. C. Y. Jung, T. S. Zhao, L. Zeng, and P. Tan, J. Power Sources, 331, 82 (2016).

21. Z. Fu, X. Lin, T. Huang, and A. Yu, J. Solid State Electrochem., 16, 1447 (2012).

22. E. M. Garcia, H. A. Tarôco, T. Matencio, R. Z. Domingues, and J. A. F. dos Santos, Int. J. Hydrogen Energy, 37, 6400 (2012).

23. J. Cheng, M. Zhang, Y. Jiang, L. Zou, Y. Gong, B. Chi, and J. Pu, Electrochim. Acta, 191, 106 (2016).

24. C. Francia, J. Amici, E. Tasarkuyu, A. Coșkun, Ö. F. Gül, and T. Șener, Int. J. Hydrogen Energy, 41, 20583 (2016).

25. Z. H. Cui and X. X. Guo, J. Power Sources, 267, 20 (2014)

26. H. Cheng and K. Scott, J. Power Sources, 195, 1370 (2010).

27. A. Débart, A. J. Paterson, J. Bao, and P. G. Bruce, Angew. Chem., 120, 4597 (2008).

28. R. S. Kalubarme, M.-S. Cho, K.-S. Yun, T.-S. Kim, and C.-J. Park, Nano- 
technology, 22, 395402 (2011).

29. S. Ida, A. K. Thapa, Y. Hidaka, Y. Okamoto, M. Matsuka, H. Hagiwara, and T. Ishihara, J. Power Sources, 203, 159 (2012).

30. H. D. Lim, H. Song, J. Kim, H. Gwon, Y. Bae, K.-Y. Park, J. Hong, H. Kim, T. Kim, Y. H. Kim, X. Lepró, R. Ovalle-Robles, R. H. Baughman, and K. Kang, Angew. Chem., Int. Ed., 53, 3926 (2014).

31. W.-J. Kwak, D. Hirshberg, D. Sharon, H.-J. Shin, M. Afri, J.-B. Park, A. Garsuch, F. F. Chesneau, A. A. Frimer, D. Aurbach, and Y.-K. Sun, J. Mater. Chem. A Mater. Energy Sustain., 3, 8855 (2015).

32. Z. Liang and Y.-C. Lu, J. Am. Chem. Soc., 138, 7574 (2016).

33. X. Xin, K. Ito, and Y. Kubo, ACS Appl. Mater. Interfaces, 9, 25976 (2017).

34. B. J. Bergner, A. Schürmann, K. Peppler, A. Garsuch, and J. Janek, J. Am. Chem. Soc., 136, 15054 (2014)

35. Y. Wang and Y. Xia, Nat. Chem., 5, 445 (2013).

36. J.-J. Xu, D. Xu, Z.-L. Wang, H.-G. Wang, L.-L. Zhang, and X.-B. Zhang, Angew.
Chem., Int. Ed., 52, 3887 (2013)

37. Y. Zhao, L. Xu, L. Mai, C. Han, Q. An, X. Xu, X. Liu, and Q. Zhang, Proc. Natl. Acad. Sci. U.S.A., 109, 19569 (2012).

38. M. Saito, S. Kosaka, T. Fujinami, Y. Tachikawa, H. Shiroishi, D. Streich, E. J. Berg, P. Novák, and S. Seki, Electrochim. Acta, 252, 192 (2017).

39. W.-H. Ryu, T.-H. Yoon, S. H. Song, S. Jeon, Y.-J. Park, and I.-D. Kim, Nano Lett., 13, 4190 (2013).

40. J. P. Lukaszewicz, S. Imaizumi, M. Yuasa, K. Shimanoe, and N. Yamazoe, J. Mater. Sci., 41, 6215 (2006)

41. S. Chung, H. Kang, J. D. Ocon, J. K. Lee, and J. Lee, Curr. Appl. Phys., 15, 1539 (2015).

42. W. G. Hardin, D. A. Slanac, X. Wang, S. Dai, K. P. Johnston, and K. J. Stevsom, J. Phys. Chem. Lett., 4, 1254 (2013).

43. T. Li, J. Liu, X. Jin, F. Wang, and Y. Song, Electrochim. Acta, 198, 115 (2016)

44. D. S. Kim and Y. J. Park, J. Alloys Compd., 591, 164 (2014). 